\title{
Shogaol, Bisdemethoxycurcumin, and Curcuminoid: Potential Zingiber Compounds Against COVID-19
}

\author{
Indah Rakhmawati Afrida 1, 2, *(i), Fatchiyah Fatchiyah 1(i), Nashi Widodo 1(D), Mohamad Amin ${ }^{3(D)}$, \\ Muhammad Sasmito Djati ${ }^{1}$ iD \\ 1 Biology Department, Faculty of Mathematics and Natural Sciences, Brawijaya University, Malang 65145, East Java, \\ Indonesia \\ 2 Biology Education Program, Faculty of Teacher Training and Education, University of Muhammadiyah Jember, Jember, \\ East Java, Indonesia \\ 3 Biology Department, Faculty of Mathematics and Natural Sciences, State University of Malang, Malang 65145, East Java, \\ Indonesia \\ * Correspondence: indahrakhmawatiafrida@unmuhjember.ac.id;
}

Scopus Author ID 56403414400

Received: 22.12.2020; Revised: 18.01.2021; Accepted: 24.01.2021; Published: 31.01.2021

\begin{abstract}
Coronavirus disease (COVID-19) is a global pandemic in the world. Some treatments, including vaccines and potential drugs, are still developed. This study investigated the bioactive compounds of Zingiber officinale, Kaempferia rotunda, and Curcuma zedoaria as a potential inhibitor for ACE2 and RdRP proteins. Molecular docking was used for screening the bioactive compounds as ACE2 and RdRP inhibitors. Shogaol (CID 5281794), zingerone (CID 31211), chalcone (CID 637760), Ar-turmerone (CID 558221), bisdemothxycurcumin (CID 5315472), and curcuminoid (CID 101341353) interacted with angiotensin-converting enzyme receptor-2/ACE2 (PDB ID 2xd3) and RNA dependent RNA polymerase/RdRP (PDB ID 6xqb), then analyzed using Discovery studio v.19 program. Shogaol, zingerone, chalcone, ar-turmerone, bisdemethoxycurcumin, and curcuminoid bound to ACE2 and RdRP protein in some active sites. Zingerone, chalcone, and ar-turmerone are attached to the ACE- 2 and then RdRP protein in similar active sites, suggesting those compounds stabilize the complex ACE-2 and RdRP protein. Shogaol interacted with the RdRP and ACE2 protein amino acid residues in the Shogaol-RdRP+ACE2 complex, indicating shogaol blocks the RdRP-ACE2 interaction. Then, bisdemethoxycurcumin and curcuminoid change the binding sites of ACE2 and RdRP protein when both compounds are bound to RdRP protein. This study suggested that shogaol, bisdemethoxycurcumin, and curcuminoid are potential drugs for COVID-19 prevention.
\end{abstract}

Keywords: ACE2; COVID-19; curcuma; ginger; RdRP protein.

(C) 2021 by the authors. This article is an open-access article distributed under the terms and conditions of the Creative Commons Attribution (CC BY) license (https://creativecommons.org/licenses/by/4.0/).

\section{Introduction}

Severe acute respiratory coronavirus syndrome-2 (SARS-COV-2) caused Coronavirus disease (COVID-19) that spread rapidly worldwide [1-3]. December 2020, more than 82 million cases have been confirmed. COVID-19 killed more communities on a daily or weekly basis on cardiovascular disease, diabetes, and other diseases [3]. Several drugs and treatments involving vaccines are still undergoing to prevent SARS-COV-2 infections. The SARS-COV2 is a single strand RNA with 14 open reading frames (ORFs) that code 27 structural and nonstructural proteins. The SARS-COV-2 protein is divided into two crucial structures, 5'-end encoding non-structural proteins and 3'-end encoded structural proteins. The non-structural protein of SARS-COV-2 proteins is multi domain protein/pro-poli protein, chymotrypsin like, 
helicase and RNA dependent RNA polymerase (RdRP). The structural protein of SARS-COV2 protein included spike surface glycoprotein, envelope, nucleocapsid, and matrix [4-7].

The infection mechanism of SARS-COV-2 in humans has been reported. The spike glycoprotein of SARS-COV-2 is attached to the receptor of angiotensin-converting enzyme-2 (ACE2) in an epithelial cell on nasopharynx tissue [1, 8-10]. Then the coronavirus released their RNA and replicated and produced the other genome coronavirus. The RdRP protein is a non-structural protein that played a crucial role in genome replication $[6,7]$. The $R d R p$ is associated with nsp7 and nsp8 as Auxiliary factors to synthesize viral RNA [5]. Two possible drug target designs for preventing COVID-19 infection, the first drug targeted to the viral directly and the second targeted to the human cell infection [4, 11-13].

The viral entry of SARS-CoV-2, immunity enhancement, and non-structural protein inhibitor seems to be a possible target for antiviral drug discovery. Malin et al. [14] reported that remdesivir and chloroquine effectively control the 2019-nCoV infection in vitro. Plant compounds and their derivates are often used to minimize toxins and promote healing [15]. Ginger rhizome has the largest polyphenol component, consisting of gingerol and shogaol, flavonoids [16-18]. S et al. [19] reported that 10-shogaol content inhibits ACE, Tiring et al. [16] showed 6-shogaol and 8-shogaol activity blocks cJun NH2-terminal Kinase protein. Kaempferia, another Zingiberace with pharmacological function, including anti-cancer, antiinflammatory, antimicrobial, Anticholinesterase, and antioxidant anti-allergic, and anti-injury properties [20]. Curcuma zedoaria or white turmeric is a plant found in the Indonesian region in the Zingiberaceae family. White turmeric is an annual plant that has antimicrobial properties [21]. This study predicted the bioactive compounds from Zingiber officinale, Kaempferia rotunda, and Curcuma zedoaria to inhibit the interaction between ACE2-RdRP SARS-COV2.

\section{Materials and Methods}

\subsection{Ligand and protein data mining.}

The bioactive compounds from Zingiber officinale including Shogaol (CID 5281794) and ZINGERONE (CID 31211), Kaempferia rotunda (chalcone, CID 637760), and Curcuma zedoaria involved Ar-turmerone (CID 558221), Bisdemothxycurcumin (CID 5315472), and Curcuminoid (CID 101341353) were downloaded from PubChem database. Angiotensinconverting enzyme receptor- 2 and RdRP proteins were taken out from PDB database with ID $2 \mathrm{xd} 3$ and $6 \mathrm{xqb}$, respectively.

\subsection{Molecular docking.}

Ligands were prepared using PyRx 0.8 [22], ACE-2, and RdRP proteins were prepared by Discovery studio v.19 software. Ligands and Proteins were docked and analyzed using the Hex 8.0.0 Software. Energy calculations are performed with each of these servers. The 3D visualization of the docking results is viewed using the Discovery Studio v.19 programs to analyze amino acid residues, energy bonds, van der Waals forces, and hydrogen bonds formed $[15,16]$. 


\section{Results and Discussion}

The complex protein of ACE 2-shogaol and ACE2-shogaol+RdRP showed interaction in three amino acid residues in the same residues involved LEU333, THR334, and PRO336 (Figure 1). Both of those complex performed binding energy $-170.76 \mathrm{cal} / \mathrm{mol}$ and -455.56 $\mathrm{cal} / \mathrm{mol}$, respectively. Shogaol interacted with RdRP protein in several binding sites: ARG553, VAL792, PHE793, PRO620, LYS621, VAL166 ASP161 proved binding energy -261.07 cal/mol. The RdRP-Shogaol-ACE2 revealed some active site residues ARG553, VAL792, PHE793, PRO620, LYS621, VAL166, ASP161, and LYS353 with binding energy -596.83 $\mathrm{cal} / \mathrm{mol}$ (Figure 1). Similar active sites of ACE 2-shogaol and ACE2-shogaol+RdRP suggested that shogaol stabilize ACE-2 and RdRP protein interaction. In RdRP-Shogaol+ACE2 complex protein, shogaol bound in between RdRp and ACE2 receptor. The binding energy of complex ACE2-shogaol+RdRP and RdRP-Shogaol+ACE2 were lower than ACE 2-shogaol and RdRPshogaol.

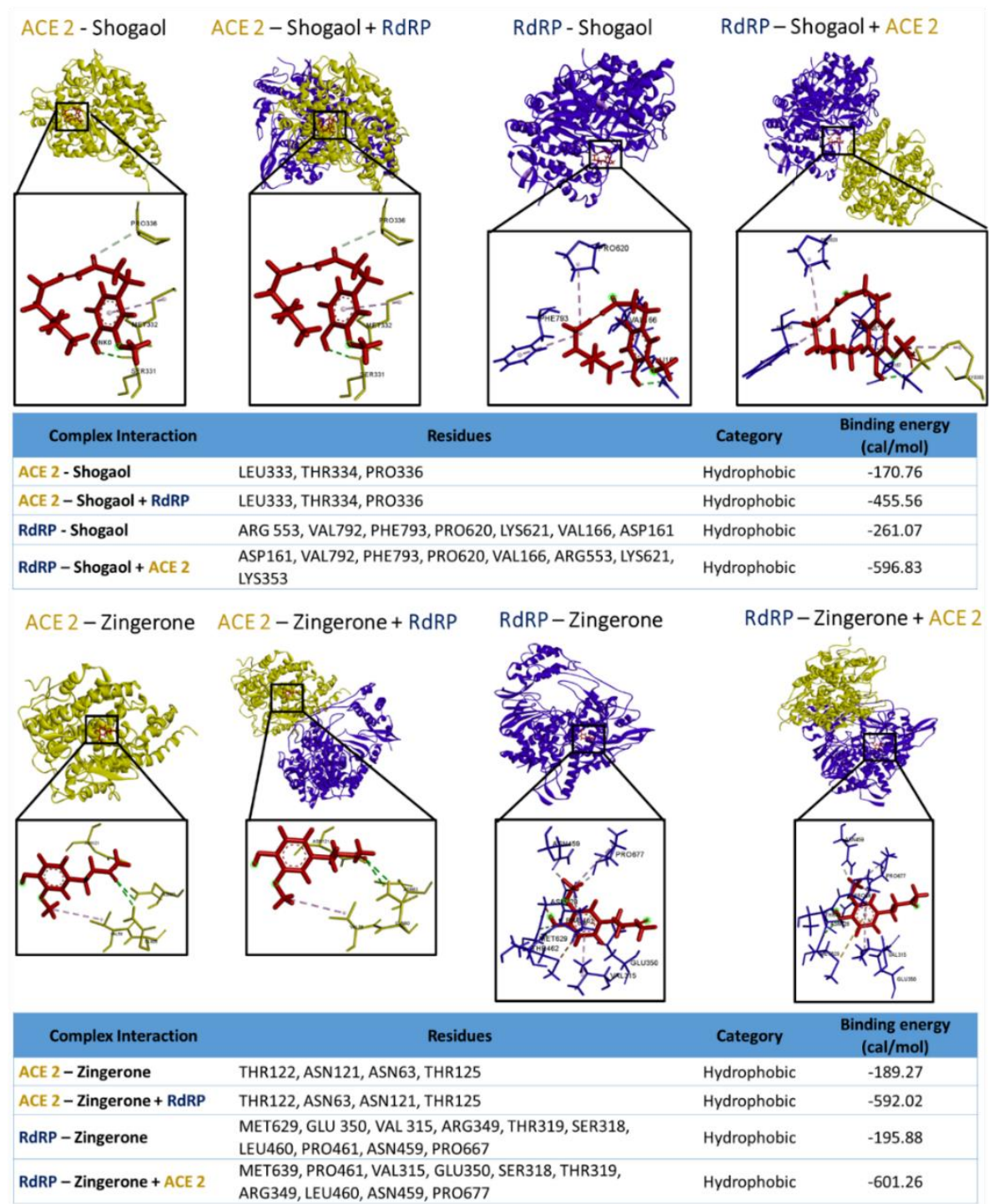

Figure 1. The interaction among shogaol and zingerone with ACE2 and RdRp SARSCOV2 protein. The yellow color is ACE2 protein, the blue color is RdRp SARSCOV2 protein, and the red color showed ligands.

Zingerone bound to ACE 2 protein at THR122, ASN121, ASN63, and THR12 of ACE2. ACE 2-Zingorone and ACE 2-Zingorone+RdRP performed binding energy -189.27 $\mathrm{cal} / \mathrm{mol}$ and $-592.02 \mathrm{cal} / \mathrm{mol}$. RdRP-Zingerone showed amino acid residues:MET629, 
GLU350, VAL315, ARG349, THR319, SER318, LEU460, PRO461, ASN459, PRO667 with binding energy $-195.88 \mathrm{cal} / \mathrm{mol}$. The RdRP-Zingerono+ACE 2 complex proved binding sites, including MET639, PRO461, VAL315, GLU350, SER318, THR319, ARG349, LEU460, ASN459, and PRO677, with binding energy $-601.26 \mathrm{cal} / \mathrm{mol}$ (Figure 1). Zingerone interacted with RdRP in different amino acid residues, suggesting zingerone moving out when ACE2 interacted with RdRP.

ACE 2-Chalcone interaction formed amino acid residue in PRO583, ASN580, GLY575, LYS553, GLN542, VAL574, GLU527 energy -210.13 cal/mol. Complex ACE 2Chalcone-RdRP showed amino acid residues PRO583, ASN580, VAL573, GLN524, LYS553, GLY575, and GLU527 with energy $-586.36 \mathrm{cal} / \mathrm{mol}$. Interaction RdRP-Chalcone released amino acid residues ASN459, ASN628, PRO627, PRO677, MET629, PRO461, SER318, ARG349, THR319, LEU460, and MET626 energy -221.61cal/mol (Figure 2). RdRPChalcone-ACE 2 showed some residues, PRO627, THR462, MET629, ASN628, SER318, ARG349, THR319, ASN459, PRO677, LEU460, PRO461, and MET626 and resulted in binding energy $-603.25 \mathrm{cal} / \mathrm{mol}$ (Figure 2).

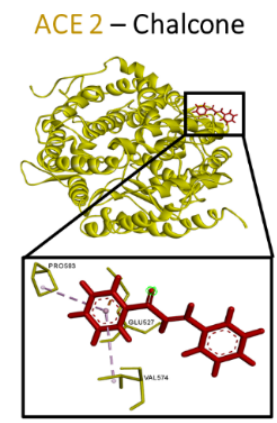

ACE 2 - Chalcone + RdRP

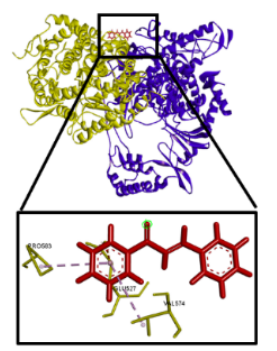

\begin{tabular}{|l|}
\hline \multicolumn{1}{|c|}{ Complex Interaction } \\
\hline ACE 2 - Chalcone \\
\hline ACE 2 - Chalcone + RdRP \\
\hline RdRP - Chalcone \\
\hline RdRP - Chalcone + ACE 2 \\
\hline
\end{tabular}
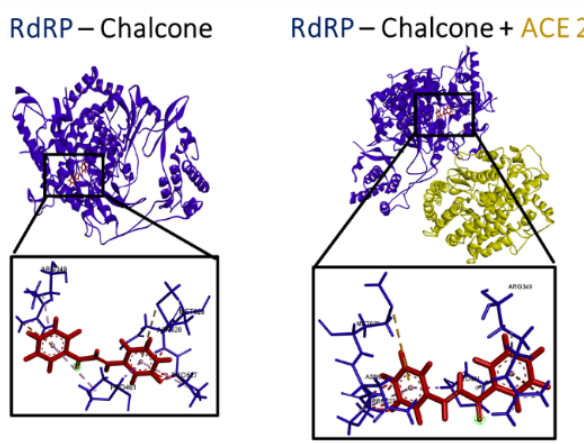

PRO583, ASN 580, GLY575, LYS553, GLN524, VAL574, GLU527 PRO583, ASN 580, VAL574, GLN524, LYS553, GLY575, GLU527 ASN459, ASN628, PRO627, PRO677, MET629, PRO461, SER318, ARG349, THR319, LEU460, MET626 PRO627, THR462, MET629, ASN628, SER318, ARG349, THR319, ASN459, PRO677, LEU460, PRO461, MET626

\begin{tabular}{|cc|}
\hline Category & $\begin{array}{c}\text { Binding energy } \\
\text { (cal/mol) }\end{array}$ \\
\hline Hydrophobic & -210.13 \\
\hline Hydrophobic & -586.36 \\
\hline Hydrophobic & -222.61 \\
\hline Hydrophobic & -603.25
\end{tabular}

Figure 2. The interaction between chalcone with ACE2 and RdRp SARSCOV2 protein. The yellow color is ACE2 protein, the blue color is RdRp SARSCOV2 protein, and the red color showed ligands.

Ar-turmerone interacts with the ACE2 receptor in VAL574, while the ACE2-Arturmerone complex binds to RdRP protein, showing VAL574 and PRO260. The other complexes were RdRP-Ar turmerone and RdRP-Ar tumerone+ACE2, both of them proved the same residues (Figure 3). Bisdemothyxcurcuminoid formed a complex with ACE2 receptor and RdRP protein in the same active sites, indicating that bisdemothyxcurcuminoid stabilize the interaction between ACE2 and RdRP protein. Interestingly, bisdemothyxcurcuminoid change the binding sites of ACE2 and RdRP protein when bisdemothyxcurcuminoid associated with RdRP protein.

Curcuminoid also stabilized the interaction between ACE2 and RdRP protein when curcuminoid blocked ACE2 protein, even though the curcuminoid showed different amino acid residues in ACE2-curcuminoid and ACE2-curcuminoid+RdRP complexes. The RdRPcurcuminoid protein complex proved various active sites with RdRP-curcuminoid+ACE2. Remarkably, RdRP-curcuminoid+ACE2 performed a higher number of active sites and changed the ACE2-RdRP complex protein's binding sites. The ligand-protein complex's binding site and three-dimensional structures revealed that bisdemothyxcurcuminoid and 
curcuminoid might have the ability to be antiviral through RdRP blocking. According to the binding energy data, the complex protein of turmeric compounds-ACE2-RdRP was lower than the turmeric compound's interaction with ACE2 or RdRP protein. The lower binding sites were supported by the high number of hydrogen and hydrophobic interactions.
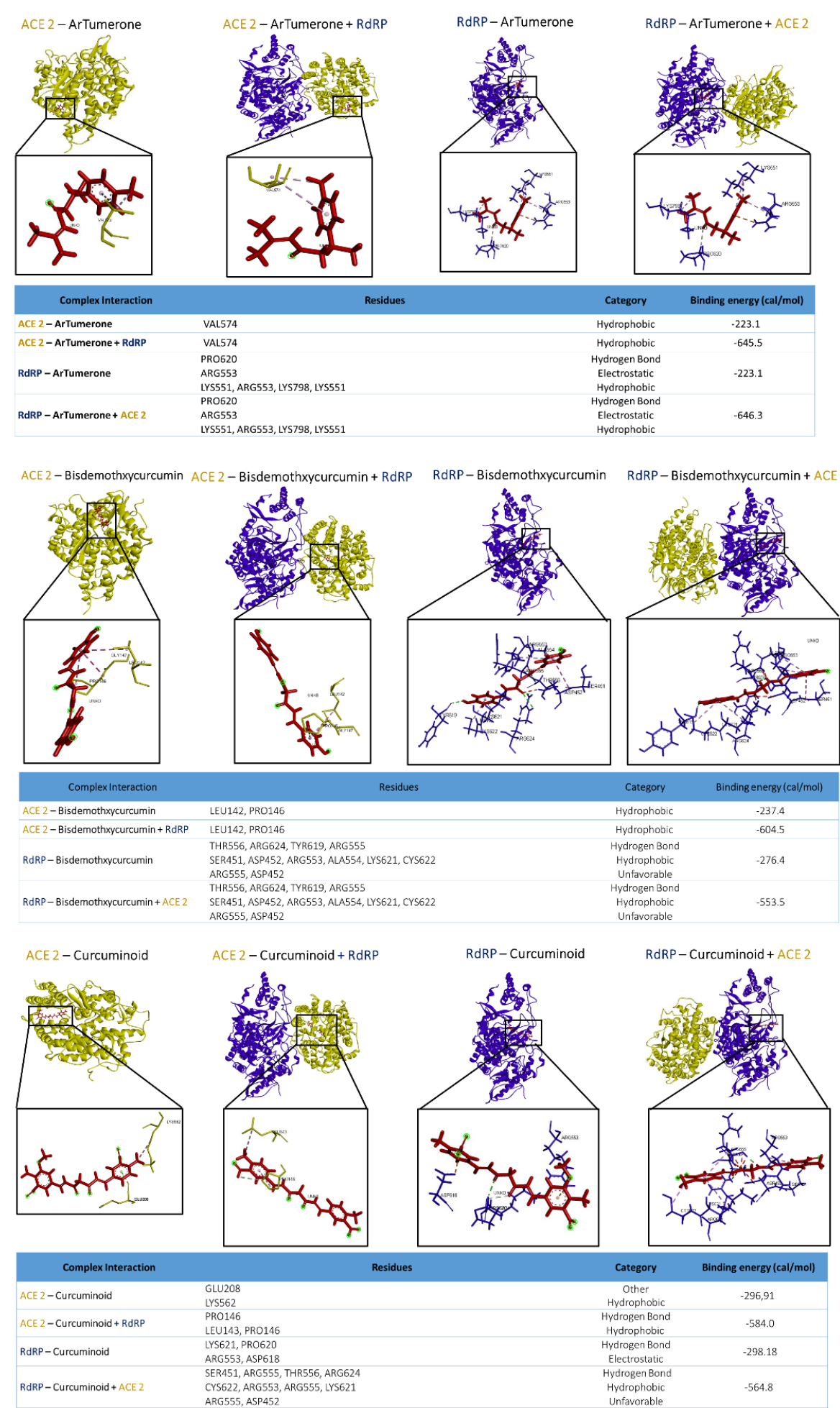

Figure 3. The interaction among turmeric compounds (Ar Tumerone, Bisdemothxycurcumin, and curcuminoid) with ACE2 and RdRp SARSCOV2 protein. The yellow color is ACE2 protein, the blue color is RdRp SARSCOV2 protein, and the red color showed turmeric compounds as ligands.

Viral entry and genome replications are the crucial targets for preventing the COVID19 from spreading. The RNA-dependent RNA polymerase (RdRp) is a non-structural protein- 
12 (nsp12), which was the most important protein for coronavirus replication/transcription complex [6, 7, 9, 23, 24]. Previous studies reported curving the COVID-19. Some bioactive such as remdesivir, favipiravir, and penciclovir as antiviral agents were used to blocking the RdRp virus [25-28]. In this case, we found compounds from Zingiber officinale is Shogaol and Zingerone, Kaempferia rotunda, Chalcone and Curcuma zedoaria involved Ar-turmerone, bisdemothxycurcumin, and curcuminoid. Those bioactive compounds interacted both on ACE2 and RdRP proteins. We found those compounds are binding with the amino acid residues in various active sites both of RdRP and ACE-2 receptor. A recent study revealed that $\mathrm{Zn}$ is a stabilizing cofactor of RdRP protein bound to His295, Cys301, Cys306, and Cys310 of RdRP residues. Zink ion is also attached to RdRP protein in the finger domain, Cys487, His642, Cys645, and Cys646 [5, 29]. In this study, potential compounds involved shogaol, bisdemethoxycurcumin, and curcuminoid were discovered as RdRP inhibitors. A previous study explored and informed that ribavirin, sofosbuvir, baloxavir, dasabuvir, galidesivir, pimodivir, and beclabuvir an antiviral drug with RdRP as targeted protein [7]. Some polyphenols reported as COVID-19 prevention, resveratrol, curcumin, and emodin inhibit the interaction between ACE-2 and spike glycoprotein through spike glycoprotein. The other compounds bound to spike glycoprotein were naringenin, epigallactocathecin gallate, hesperidin, tangeretin, and curcumin derivates [23, 27].

The complex protein of bioactive compounds in ginger, Kaempferia, and turmeric with ACE2 and RdRP were lower than the complex of bioactive compounds-ACE2 or bioactive compounds-RdRP. The binding energy caused close interaction in ligand-protein interaction. Some interactions contributing to the binding energy were hydrogen bonds, hydrophobic interaction, electrostatic, and van der Waals [30-32]. Binding energy correlated with binding affinity, depending on $\mathrm{H}$-bond and altering one or more atoms in compounds that interacted with the protein target. Besides that, the H-bond mixed with disulfide bonds decreased the binding affinity in ligand-protein interaction [33]. Hydrogen bonds and hydrophobic interaction were important to enhance the optimum drug design [30-33]. In the current study, the molecular docking among bioactive compounds of ginger, Kaempfera, and turmeric with ACE2 and or RdRP protein was dominant with hydrophobic interactions. The number hydrogen bond was only showed in turmeric complex with ACE2 and or RdRP protein. A previous study reported that the interaction of $\mathrm{S} 2$ protein of SARSCOV2 and ACE2 promoted hydrophobic interaction, which caused hydrophilic residues in this area, releasing hydrogen in water molecules and promoting hydrogen electrostatic bonds $[34,35]$. In the current study, the complex bioactive constituents revealed a lowering binding affinity of ACE2-RdRP proteins, greatly decreasing the COVID-19 infectious.

\section{Conclusions}

Virtual screening of bioactive compounds from Zingiber officinale, Kaempferia rotunda, and Curcuma zedoaria suggested shogaol, bisdemothxycurcumin, and curcuminoid have a potential activity to reduce the effect of ACE2 -RdRp SARSCOV2 protein interaction through RdRP inhibition.

\section{Funding}

This research was supported by Universitas Muhammadiyah Jember 2020. 


\section{Acknowledgments}

The authors also thank Dewi Ratih Tirto Sari for technical assistance throughout this work.

\section{Conflicts of Interest}

No conflict of interest declared.

\section{References}

1. Alexpandi, R.; De Mesquita, J.F.; Pandian, S.K.; Ravi, A.V. Quinolines-Based SARS-CoV-2 3CLpro and RdRp Inhibitors and Spike-RBD-ACE2 Inhibitor for Drug-Repurposing Against COVID-19: An in silico Analysis. Frontiers in Microbiology 2020, 11, 1-15, https://doi.org/10.3389/fmicb.2020.01796.

2. Kasozi, K.I.; Niedbała, G.; Alqarni, M.; Zirintunda, G.; Ssempijja, F.; Musinguzi, S.P.; Usman, I.M.; Matama, K.; Hetta, H.F.; Mbiydzenyuy, N.E.; Batiha, G.E.-S.; Beshbishy, A.M.; Welburn, S.C. Bee Venom-A Potential Complementary Medicine Candidate for SARS-CoV-2 Infections. Frontiers in Public Health 2020, 8, https://doi.org/10.3389/fpubh.2020.594458.

3. Singhal, T. Review on COVID19 disease so far. The Indian Journal of Pediatrics 2020, 87, 281-286, https://doi.org/10.1007/s12098-020-03263-6.

4. Gao, Y.; Yan, L.; Huang, Y.; Liu, F.; Zhao, Y.; Cao, L.; Wang, T.; Sun, Q.; Ming, Z.; Zhang, L.; Ge, J.; Zheng, L.; Zhang, Y.; Wang, H.; Zhu, Y.; Zhu, C.; Hu, T.; Hua, T.; Zhang, B.; Yang, X.; Li, J.; Yang, H.; Liu, Z.; Xu, W.; Guddat, L.W.; Wang, Q.; Lou, Z.; Rao, Z. Structure of the RNA-dependent RNA polymerase from COVID-19 virus. Science 2020, 368, 779-782, https://doi.org/10.1126/science.abb7498.

5. Hillen, H.S.; Kokic, G.; Farnung, L.; Dienemann, C.; Tegunov, D.; Cramer, P. Structure of replicating SARS-CoV-2 polymerase. Nature 2020, 584, 154-156, https://doi.org/10.1038/s41586-020-2368-8.

6. Ahmad, J.; Ikram, S.; Ahmad, F.; Rehman, I.U.; Mushtaq, M. SARS-CoV-2 RNA Dependent RNA polymerase (RdRp) - A drug repurposing study. Heliyon 2020, 6 , https://doi.org/10.1016/j.heliyon.2020.e04502.

7. Zhu, W.; Chen, C.Z.; Gorshkov, K.; Xu, M.; Lo, D.C.; Zheng, W. RNA-Dependent RNA Polymerase as a Target for COVID-19 Drug Discovery. SLAS DISCOVERY: Advancing the Science of Drug Discovery 2020, 25, 1141-1151, https://doi.org/10.1177/2472555220942123.

8. $\quad$ Robinson, F.A.; Mihealsick, R.P.; Wagener, B.M.; Hanna, P.; Poston, M.D.; Efimov, I.R.; Shivkumar, K.; Hoover, D.B. Role of angiotensin-converting enzyme 2 and pericytes in cardiac complications of COVID19 infection. American Journal of Physiology-Heart and Circulatory Physiology 2020, 319, H1059-H1068, https://doi.org/10.1152/AJPHEART.00681.2020.

9. Jamalipour Soufi, G.; Iravani, S. Potential inhibitors of SARS-CoV-2: recent advances. Journal of Drug Targeting 2020, 10, 1-52, https://doi.org/10.1080/1061186x.2020.1853736.

10. Bourgonje, A.R.; Abdulle, A.E.; Timens, W.; Hillebrands, J.-L.; Navis, G.J.; Gordijn, S.J.; Bolling, M.C.; Dijkstra, G.; Voors, A.A.; Osterhaus, A.D.M.E.; van der Voort, P.H.J.; Mulder, D.J.; van Goor, H. Angiotensin-converting enzyme 2 (ACE2), SARS-CoV-2 and the pathophysiology of coronavirus disease 2019 (COVID-19). The Journal of Pathology 2020, 251, 228-248, https://doi.org/10.1002/path.5471.

11. Zhang, S.; Krumberger, M.; Morris, M.A.; Parrocha, C.M.T.; Griffin, J.H.; Kreutzer, A.; Nowick, J.S. Structure-Based Drug Design of an Inhibitor of the SARS-CoV-2 (COVID-19) Main Protease Using Free Software: A Tutorial for Students and Scientists. ChemRxiv 2020, 2, https://doi.org/10.26434/chemrxiv.12791954.

12. Elfiky, A.A. SARS-CoV-2 RNA dependent RNA polymerase (RdRp) targeting: an in silico perspective. Journal of Biomolecular Structure and Dynamics 2020, 10, 1-9, https://doi.org/10.1080/07391102.2020.1761882.

13. De Clercq, E.; Li, G. Approved Antiviral Drugs over the Past 50 Years. Clinical Microbiology Reviews 2016, 29, 695-747, https://doi.org/10.1128/CMR.00102-15.

14. Malin, J.J.; Suárez, I.; Priesner, V.; Fätkenheuer, G.; Rybniker, J. Remdesivir against COVID-19 and Other Viral Diseases. Clinical Microbiology Reviews 2020, 34, 1-21, https://doi.org/10.1128/CMR.00162-20.

15. Bare, Y.; Sari, D.; Rachmad, Y.; Krisnamurti, G.; Elizabeth, A. In Silico Insight the Prediction of Chlorogenic Acid in Coffee through Cyclooxygenase-2 (COX2) Interaction. Biogenesis: Jurnal Ilmiah Biologi 2019, 7, 100-105, https://doi.org/10.24252/bio.v7i2.9847.

16. Tiring, S.; Bare, Y.; Maulidi, A.; S, M.; Nugraha, F.A.D. Studi In Silico: Prediksi Potensi 6-shogaol dalam Zingiber officinale sebagai Inhibitor JNK. Al-Kimia 2019, 7, 147-153, https://doi.org/10.24252/alkimia.v7i2.10638.

17. Mao, Q.-Q.; Xu, X.-Y.; Cao, S.-Y.; Gan, R.-Y.; Corke, H.; Beta, T.; Li, H.-B. Bioactive Compounds and Bioactivities of Ginger (Zingiber officinale Roscoe). Foods 2019, 8, 1-21, https://doi.org/10.3390/foods8060185. 
18. Bare, Y.; S, M.; Tiring, S.; Sari, D.; Maulidi, A. Virtual Screening: Prediksi potensi 8-shogaol terhadap cJun N-Terminal Kinase (JNK). Jurnal Penelitian dan Pengkajian Ilmu Pendidikan: e-Saintika 2020, 4, 1-6, https://doi.org/10.36312/e-saintika.v4i1.157.

19. Mansur, S.; Bare, Y.; Helvina, M.; Pili, A.P.; Krisnamurti, G.C.J. In silico Study: Potential activity of 10shogaol in Zingiber officinale through ACE gene. Spizaetus: Jurnal Biologi dan Pendidikan Biologi 2020, $1,12-18$.

20. Elshamy, A.I.; Mohamed, T.A.; Essa, A.F.; Abd-El Gawad, A.M.; Alqahtani, A.S.; Shahat, A.A.; Yoneyama, T.; Farrag, A.R.H.; Noji, M.; El-Seedi, H.R.; Umeyama, A.; Paré, P.W.; Hegazy, M.-E.F. Recent Advances in Kaempferia Phytochemistry and Biological Activity: A Comprehensive Review. Nutrients 2019, 11, https://doi.org/10.3390/nu11102396.

21. Chachad, D.P.; Talpade, M.B.; Jagdale, S.P. Antimicrobial Activity of Rhizomes of Curcuma zedoaria Rosc. International Journal of Science and Research 2016, 5, 938-940, https://doi.org/10.21275/ART20162324.

22. Dallakyan, S.; Olson, A.J. Small molecule library screening by docking with PyRx. Methods Mol Biol 2015, 1263, 243-250, https://doi.org/10.1007/978-1-4939-2269-7_19.

23. Paraiso, I.L.; Revel, J.S.; Stevens, J.F. Potential use of polyphenols in the battle against COVID-19. Current Opinion in Food Science 2020, 32, 149-155, https://doi.org/10.1016/j.cofs.2020.08.004.

24. Shyr, Z.A.; Gorshkov, K.; Chen, C.Z.; Zheng, W. Drug Discovery Strategies for SARS-CoV-2. Journal of Pharmacology and Experimental Therapeutics 2020, 375, 127-138, https://doi.org/10.1124/JPET.120.000123.

25. Xiu, S.; Dick, A.; Ju, H.; Mirzaie, S.; Abdi, F.; Cocklin, S.; Zhan, P.; Liu, X. Inhibitors of SARS-CoV-2 Entry: Current and Future Opportunities. Journal of Medicinal Chemistry 2020, 63, 12256-12274, https://doi.org/10.1021/acs.jmedchem.0c00502.

26. Shehroz, M.; Zaheer, T.; Hussain, T. Computer-aided drug design against spike glycoprotein of SARS-CoV2 to aid COVID-19 treatment. Heliyon 2020, 6, https://doi.org/10.1016/j.heliyon.2020.e05278.

27. Poduri, R.; Joshi, G.; Jagadeesh, G. Drugs targeting various stages of the SARS-CoV-2 life cycle: Exploring promising drugs for the treatment of Covid-19. Cellular Signalling 2020, 74, https://doi.org/10.1016/j.cellsig.2020.109721.

28. Jaiswal, G.; Kumar, V. In-silico design of a potential inhibitor of SARS-CoV-2 S protein. PLOS ONE 2020, 15, 1-15, https://doi.org/10.1371/journal.pone.0240004.

29. Aftab, S.O.; Ghouri, M.Z.; Masood, M.U.; Haider, Z.; Khan, Z.; Ahmad, A.; Munawar, N. Analysis of SARS-CoV-2 RNA-dependent RNA polymerase as a potential therapeutic drug target using a computational approach. Journal of Translational Medicine 2020, 18, 1-15, https://doi.org/10.1186/s12967-020-02439-0.

30. Sari, D.R.T.; Safitri, A.; Cairns, J.R.K.; Fatchiyah, F. Anti-Apoptotic Activity of Anthocyanins has Potential to inhibit Caspase-3 Signaling. Journal of Tropical Life Science 2020, 10, 15-25, https://doi.org/10.11594/jtls.10.01.03.

31. Sari, D.R.T.; Cairns, J.R.K.; Safitri, A.; Fatchiyah, F. Virtual Prediction of the Delphinidin-3-O-glucoside and Peonidin-3-O-glucoside as Anti-inflammatory of TNF- $\alpha$ Signaling. Acta informatica medica : AIM : journal of the Society for Medical Informatics of Bosnia \& Herzegovina : casopis Drustva za medicinsku informatiku BiH 2019, 27, 152-157, https://doi.org/10.5455/aim.2019.27.152-157.

32. Raharjo, S.J.; Mahdi, C.; Nurdiana, N.; Kikuchi, T.; Fatchiyah, F. Binding Energy Calculation of Patchouli Alcohol Isomer Cyclooxygenase Complexes Suggested as COX-1/COX-2 Selective Inhibitor. Advances in Bioinformatics 2014, 2014, 1-12, https://doi.org/10.1155/2014/850628.

33. Chen, D.; Oezguen, N.; Urvil, P.; Ferguson, C.; Dann, S.M.; Savidge, T.C. Regulation of protein-ligand binding affinity by hydrogen bond pairing. Science Advances; 2016, 2, https://doi.org/10.1126/sciadv.1501240.

34. Li, J.; Ma, X.; Guo, S.; Hou, C.; Shi, L.; Zhang, H.; Zheng, B.; Liao, C.; Yang, L.; Ye, L.; He, X. A Hydrophobic-Interaction-Based Mechanism Triggers Docking between the SARS-CoV-2 Spike and Angiotensin-Converting Enzyme 2. Global Challenges 2020, 4, https://doi.org/10.1002/gch2.202000067.

35. Datta, P.K.; Liu, F.; Fischer, T.; Rappaport, J.; Qin, X. SARS-CoV-2 pandemic and research gaps: Understanding SARS-CoV-2 interaction with the ACE2 receptor and implications for therapy. Theranostics 2020, 10, 7448-7464, https://doi.org/10.7150/thno.48076. 